\title{
IMPROVED DYNAMIC PERFORMANCES OF MULTI-AREA REHEAT THERMAL AGC POWER SYSTEMS WITH ENERGY STORAGE UNIT
}

\author{
K.Jagatheesan ${ }^{1}$, B.Anand ${ }^{2}$, Abhilash Das ${ }^{3}$ \\ ${ }^{1}$ Assistant Professor, Department of Electrical and Electronics Engineering, Mahendra Institute of Engg and Tech., Na- \\ makkal, Tamilnadu, India \\ ${ }^{2}$ Department of ECE, Mahendra Institute of Engg and Tech, Namakkal, Tamilnadu, India \\ ${ }^{3}$ Associate Professor, Department of Electrical and Electronics Engineering in Hindusthan college of Engg and Tech., \\ Coimbatore, Tamilnadu, India.
}

\begin{abstract}
A fast acting energy storage SMES unit is considering for this investigation. The present paper shows the influence of SMES unit on the dynamic performance of the AGC system is investigated with PI controller. A simulink model of a three area interconnected reheat thermal power system is modeled with and without considering Super conducting Magnetic Energy Storage (SMES) unit effect. The time domain simulations are used to study the behavior of thermal power system and SMES system. The optimal gain values of $P$ and I are obtained by using ITAE performance indices. Finally the simulation results reveals that SMES unit is very effectively reducing the peak overshoot, settling time, and peak time of frequency and tie-line power deviation in the power system.
\end{abstract}

Keywords - Automatic Generation Control (AGC), Area Control Error (ACE), Energy storage unit, Interconnected power systems, Performance indices, Proportional-Integral (PI) controller, SMES unit

\section{INTRODUCTION}

In electric power system, consumption power to the consumers changes continuously at every instant of time. So maintaining of power balance at every instant, keeps the system operation in stable condition. The nominal values of frequency, voltage and tie line power flow between connected areas specifies the state of system. If the system parameters fluctuate with in the tolerable limit, then the corresponding system is said to be a controlled system and it works in nominal state. But practically $100 \%$ of power balance is not possible, that is power generation does not match with the power consumption. Due to this mismatch, system yields deviation in frequency and tie line power flow. The maximum permissible value of change in frequency is $\pm 0.5 \mathrm{~Hz}$ [13]. When the nominal operative frequency changes below its specified value, it will cause metal fatigue and blade failure in steam turbine. In order to mitigate this problem load frequency control technique is implemented. The role of LFC is to restore frequency fluctuation and tie line power flow deviation into zero. This is achieved with the help of controller; here conventional PI controller is used to make the deviation into zero [13-15].

An energy storage device having the capability to reduce the oscillation in system frequency and tie line power flow with in a quick period of time [1-5]. Many energy storage units are modeled and implemented to meet the needs with in last few decades. The units are battery energy storage, CES, fly wheels,
SMES etc. In this paper super conducting magnetic energy storage unit is implemented and it stores the energy in the form of magnetic field $[3,4]$. The stored energy is suddenly released through PCS, when there is a rise in load demand. Due to this demand, the turbine and other LFC arrangements are adjusted for the power balance and new equilibrium. SMES coil absorbs the energy during steady state operation of the system and observed energy is released during sudden load changes. The control of SMES unit is based on changing the firing angle of converter in this unit [5-9]. The effective way of using SMES unit is based on the control strategy of unit.

The main aim of the present works is

- $\quad$ To develop the MATLAB simulink model of three areas interconnected thermal power system with and without SMES unit.

- To design conventional PI controller by using ITAE indices.

- $\quad$ To compare the dynamic responses of the AGC power system with and without energy storage SMES unit

\section{MULTI-AREA REHEAT THERMAL POWER SYSTEM}

A MATLAB simulink model for AGC of a three area thermal power system with equal size is designed for this work as shown in fig.1 [10-12]. All three areas are incorporate with reheat turbine 
and interconnected through AC tie line. SMES energy unit is connected in parallel to the generator terminal in all area and area control error signal is used to control the unit. MATLAB 7.5(R2007b) has been used to obtain dynamic response for frequency deviations, tie line power flow and area control error, when $1 \%$ step load perturbation given in thermal area 1 of the system. Conventional controller gain values in all areas obtained by using Integral Time Absolute Error (ITAE) performance index criterion [12].

\subsection{Superconductiong Magnetic Energy Stroage}

\section{(SMES) Unit}

SMES is a dc current device, which store the energy in the form of magnetic field [1-4]. The basic component of this unit is superconducting coil, cryogenic system, transformer and power conversion system with proper control and protection function arrangement. From these components, superconducting coil is the heart of SMES unit. It incorporates with vacuum vessels and liquid vessels for the cooling arrangement of coil. A cryogenic system is used to keep the temperature of coil below its critical value of temperature. The PCS system is used for two purposes: one is conversion of electrical energy from $\mathrm{dc}$ to ac, another is to charge and discharge of coil. The power system is connected to the PCS with help of transformer and it also used to reduce the operating voltage into acceptable level for the PCS.

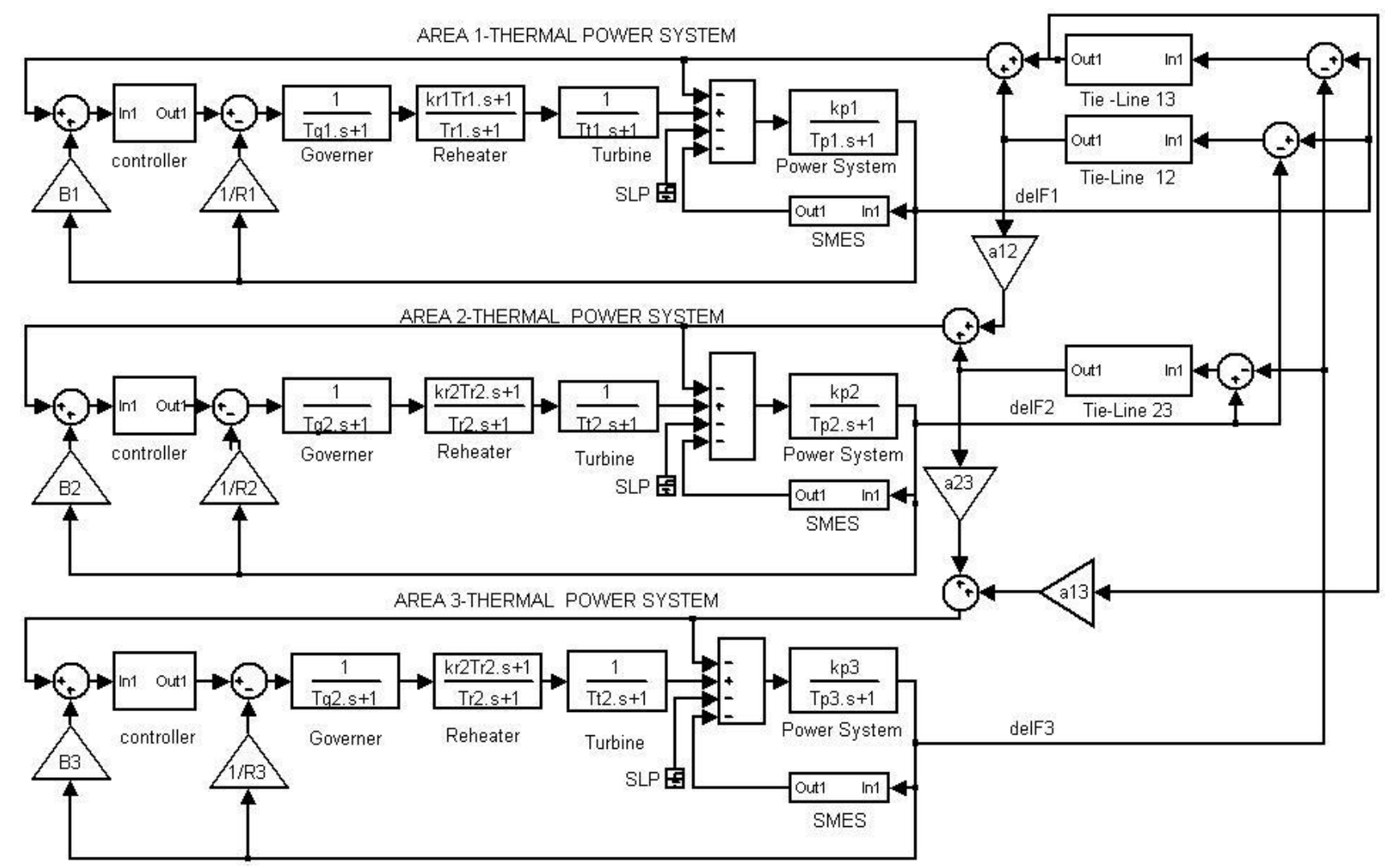

Fig 1 Transfer function of block diagram of AGC of three area thermal power system with SMES unit.t

In the SMES unit, energy is stored in the super conducting coil

(E) and the rated power $(\mathrm{P})$ is given by [3-7]

$$
E=\frac{1}{2} L I^{2}
$$

$$
P=\frac{d E}{d t}=L I \frac{d I}{d t}=V I
$$

Where

L-Inductance of the coil

$\mathrm{V}$ - voltage across the coil

I - DC current flowing through the coil 
When the superconducting coil reaches the rated current, the SMES unit is ready for AGC or LFC control. Area control Error is sensed and it is used to control the voltage of SMES unit, by changing the duty cycle of the chopper. The block diagram of SMES unit as shown in fig.2

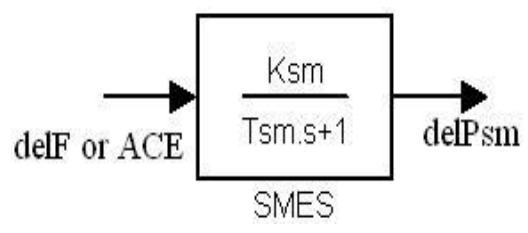

Fig 2 Block diagram of SMES unit.

\section{OPTIMIZATION OF PROPORTIONAL AND INTEGRAL CONTROLLER GAIN VALUES}

As Most commonly used conventional PI controller is implemented in thermal power system for performance comparison of system with and without SMES unit. Proportional controller having the ability to settle system very fast to its steady state level. But it does not reduce steady state error fully. To overcome this problem, integral controller is added in addition with $\mathrm{P}$ controller. Integral controller eliminate the steady state error continuously with little or vanished overshoot. Performance of the power system is fully based on the values of controller gain $\mathrm{K}_{\mathrm{i}}$ and $\mathrm{K}_{\mathrm{p}}$. So optimization of gain value is very essential to meet the controlled response. Structure of PI controller is shown in Fig.3.

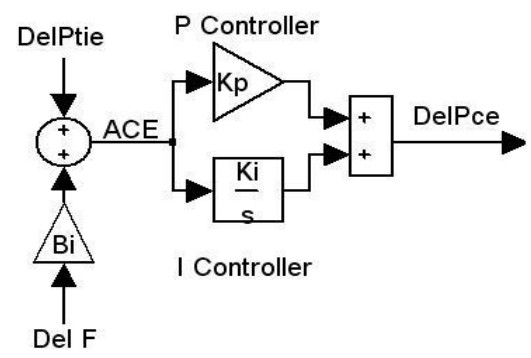

Fig 3 Structure of PI controller

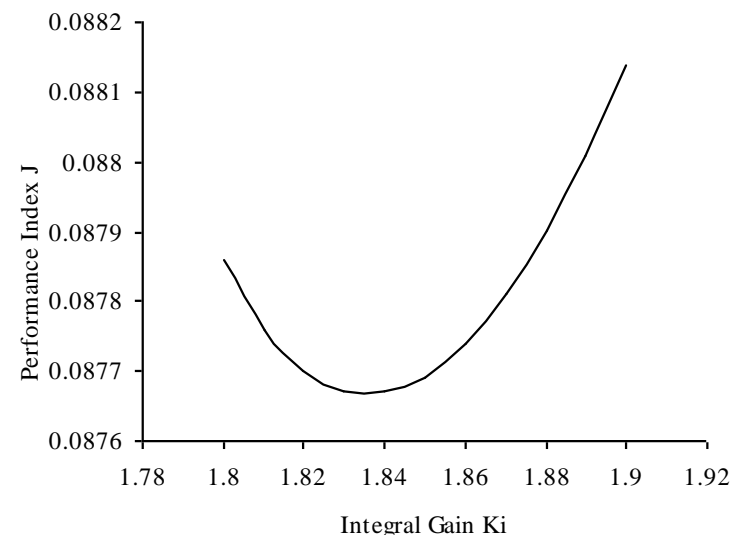

Fig 4 Performance Index $\mathrm{J}$ vs $\mathrm{K}_{\mathrm{i}}$ (with SMES unit)

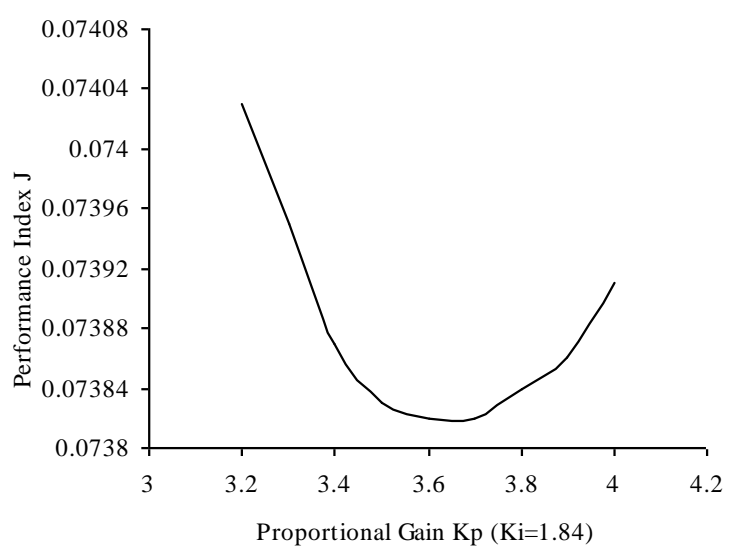

Fig 5 Performance Index $\mathrm{J}_{\text {vs }} \mathrm{K}_{\mathrm{p}}$ (with SMES unit)

\section{RESULTS AND DISCUSSION}

Simulink model of three area power system is described in section 2. From the uncontrolled response shown in fig.5\&6. It is clearly shown that, lacking of controller in the power system yield more steady state error with unsettled response. In order to mitigate this problem conventional Proportional -Integral controller is designed and controller gain values are optimized in section 3 .

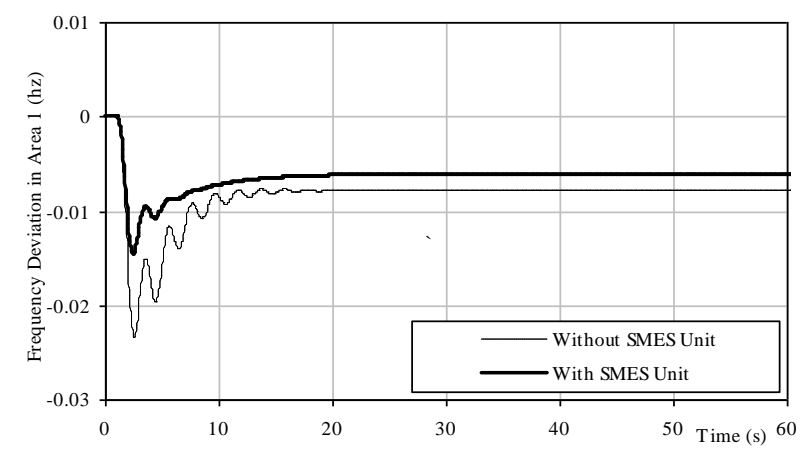

Fig 6 Uncontrolled response with and without SMES unit $\left(\mathrm{delF}_{1}\right)$

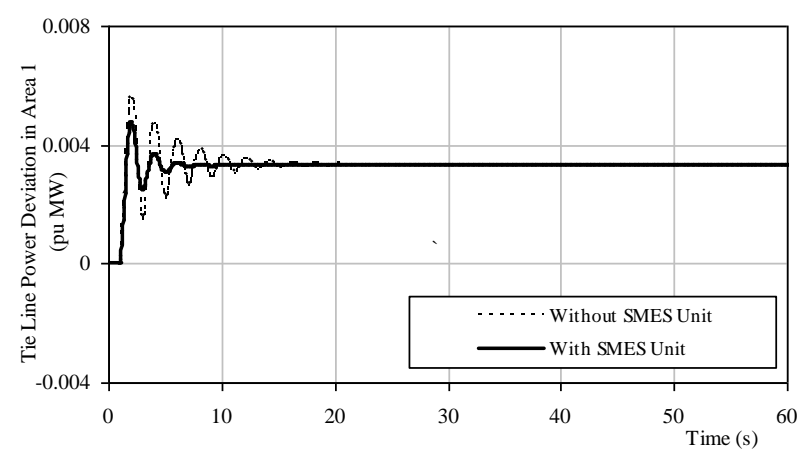

Fig 7 Uncontrolled response with and without SMES unit $\left(\right.$ delP $\left._{\text {tie } 1}\right)$ 
Dynamic performances for frequency deviations, tie line power flow deviations and area control error with and without considering SMES unit in area1, 2 and 3, are shown in the Fig.8-16. From the response, dotted response plot shows the response of system without consideration of SMES unit, whereas solid line plot shows the response of system with consideration SMES energy storage unit. By examine the response; it is clearly designate that, system yield more damping oscillations with maximum peak overshoot during absence of energy storage unit in the AGC system. But system yield better controlled response, when SMES is considered in the system operation. Performance comparison of thermal system is shown in the table 1.

Table 1: system performance comparision with and without considering smes unit

\begin{tabular}{|l|l|c|}
\hline \multirow{2}{*}{$\begin{array}{c}\text { Time domain } \\
\text { parameters }\end{array}$} & \multicolumn{2}{|c|}{$\begin{array}{c}\text { DelF } \\
\text { wnit }\end{array}$} \\
\cline { 2 - 3 } Peak overshoot & 0.0099 & With SMES wnit \\
\hline Settling Time $\left(\mathrm{T}_{\mathrm{S}}\right)$ & 39.97 & 0.00466 \\
\hline Peak time( $\left.\mathrm{T}_{\mathrm{p}}\right)$ & 4.668 & 22.21 \\
\hline Peak undershoot & 0.02223 & 2.12 \\
\hline
\end{tabular}

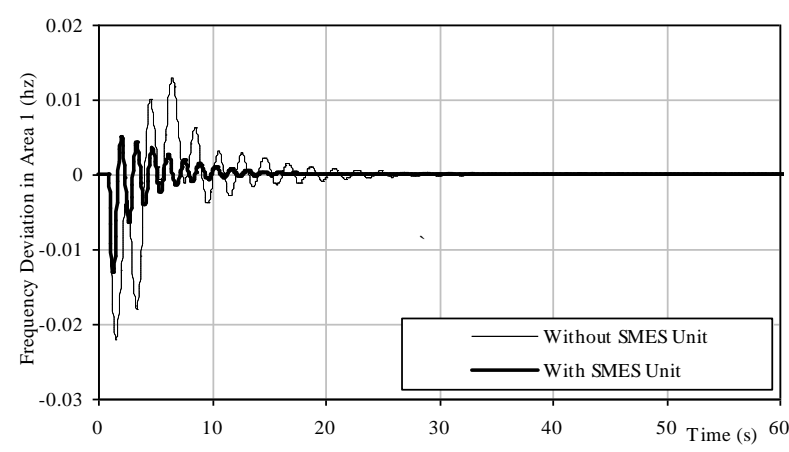

Fig 8 Controlled response with and without SMES unit $\left(\mathrm{delF}_{1}\right)$

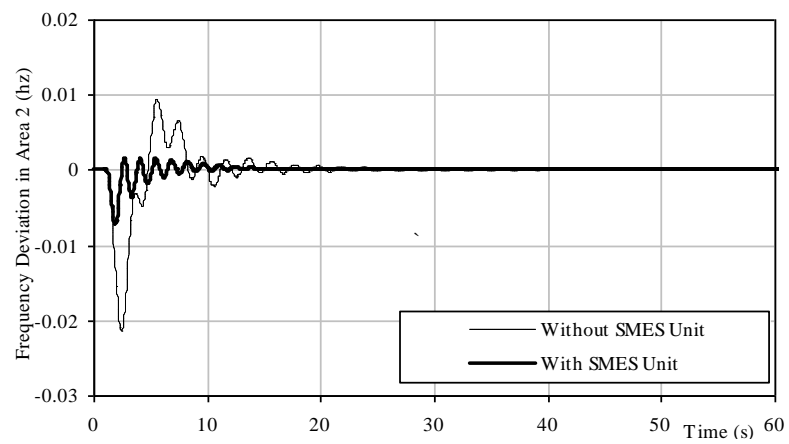

Fig 9 Controlled response with and without SMES unit $\left(\mathrm{delF}_{2}\right)$

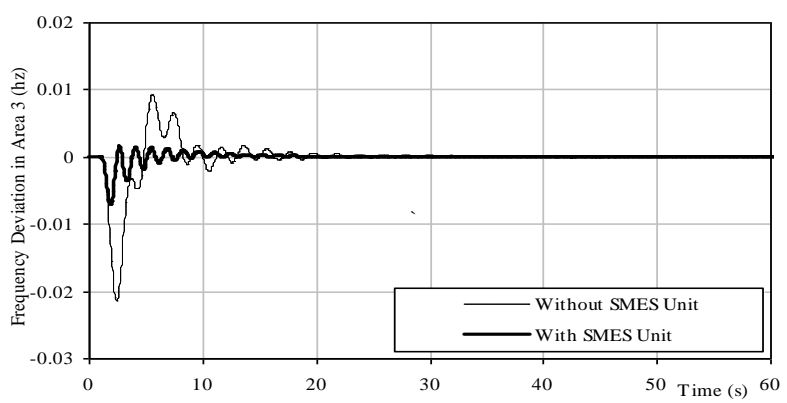

Fig 10 Controlled response with and without SMES unit $\left(\mathrm{delF}_{3}\right)$

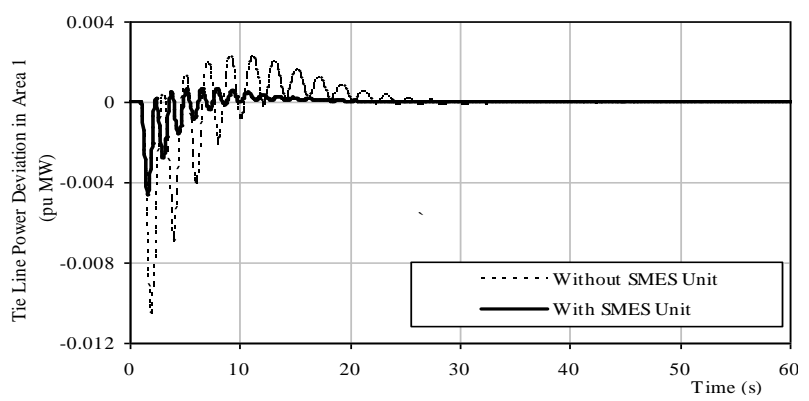

Fig 11 Controlled response with and without SMES unit (delPtie 1)

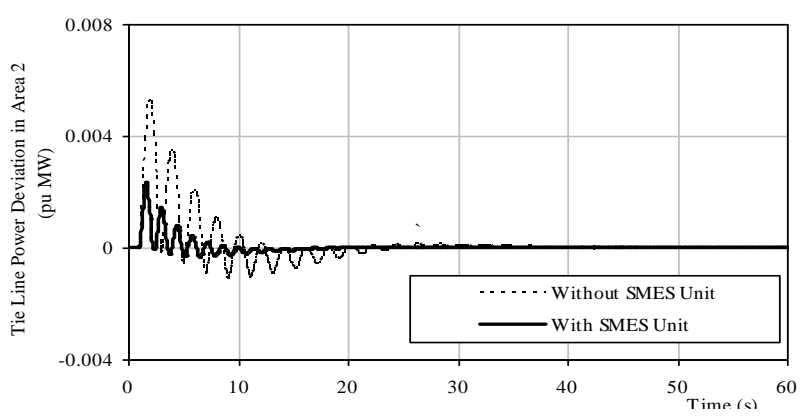

Fig 12 Controlled response with and without SMES unit (delPtie 2)

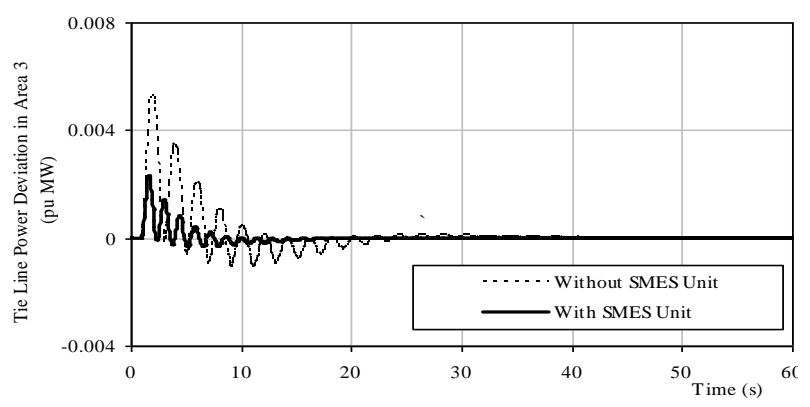

Fig 13 Controlled response with and without SMES unit (delPtie 3) 


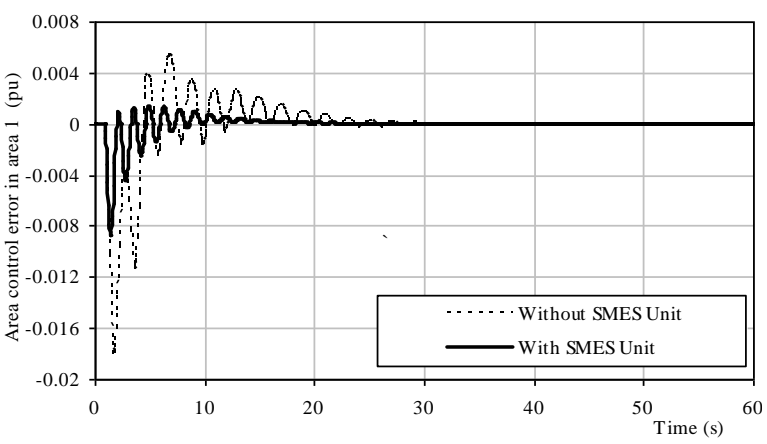

Fig 14 Controlled response with and without SMES unit (ACE 1)

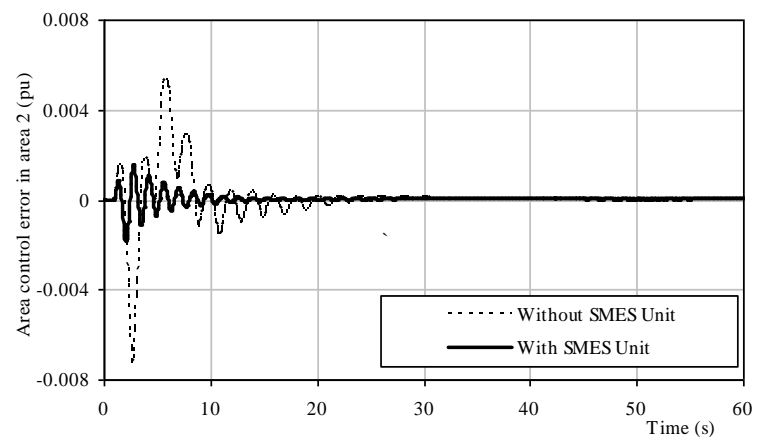

Fig 15 Controlled response with and without SMES unit $\left(\mathrm{ACE}_{2}\right)$

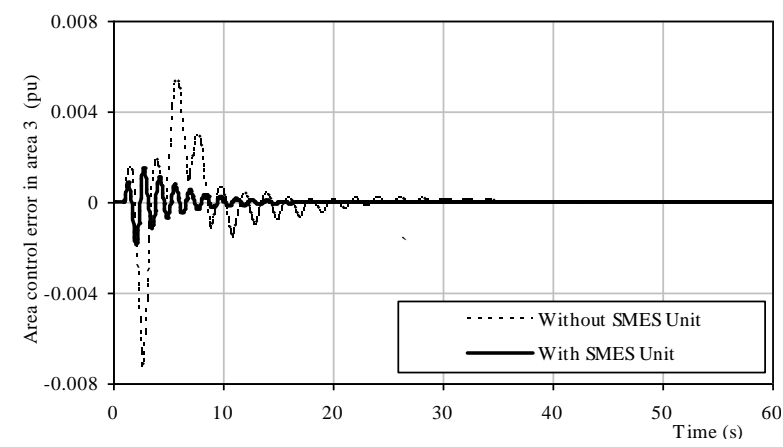

Fig 16 Controlled response with and without SMES unit (ACE 3)

\section{CONCLUSIONS}

In this work, performance of three area reheat thermal power system is improved by using SMES energy storage unit and response is compared with and without considering energy storage unit in all areas.Damping oscillations, peak overshoot, settling time are improved, when compared to the response of system without considering SMES unit.Conventional PI controller gain values are optimized using Integral Time Absolute Error (ITAE) performance index criterion.

\section{REFERENCES}

[1] T.Ise, Y.Murkami and K.Tsuji, "Simultanous active and reactive power control of SMES unit using GTO converter", IEEE transaction on power delivery, vol.PWRD-1, 1986, pp.143-150.

[2] S.C.tripathy, R.Balasubramaniam and P.S.Chandramohan Nair, "Adaptive automatic generation control with SMES in power systems", IEEE transaction on energy conversion, vol.7, 1992, pp.434-441.

[3] K.Tam, P.Kumar, "Application of SMES in an asynchronous link between power systems", IEEE transaction on energy conversion, vol.5, 1990, pp.436-444.

[4] H.A. Peterson, N.Mohan and R.W.Boom, "Superconductive energy storage inductor-converter units for power systems", IEEE transaction on power apparatus and systems, vol.PAS-94, 1975, pp.1337-1348..

[5] Y.Mitani, K.Tsuji and Y.Murkami, "Application of superconducting magnet energy storage to improve power system dynamic performance", IEEE transcation on power systems, vol.3, 1988, pp.1418-1425.

[6] S.Banerjee, J.K. Chatterjee and S.C.Tripathy, "Application of magnetic energy storagge unit as load frequency stabilizer", IEEE transaction on energy conversion, vol.5, 1990, pp.46-51.

[7] Wa-sur Tam and Prem Kumar," Applications of superconductivie magnetic energy storage in an asynchronous link between power systems", IEEE transaction on energy conversion, vol.5, 1990.

[8] S.C.tripathy, R.Balasubramaniam and P.S.Chandramohan Nair, "Effect of superconducting magnetic energy storage on automatic generation control considering governor dead and boiler dynamics", paper presented in the IEEE PES international power meeting-India, 1990, and to be published in IEEE transcation on power systems(Paper No. 90 IC 588-4 PWRS)

[9] S.C.Tripathy, G.S. Hope and O.P.Malik," pOptimization of load frequency control paprameters for power system with reheat steam turbine and governor deadband non linearity", Proceedings IEEE, vol.129,Pt.C, No.1, 1982, pp.10-16.

[10] J Nanda and J S Sakkaram, "Automatic Generation with Fuzzy logic controller considering Generation Rate Constraint," Proceedings of 6th International Conference on APSCOM, Hongkong, November 2003.

[11] B Anand, A Ebenezer Jeyakumar, "Fuzzy Logic load frequency Control of hydro - Thermal system with nonLinearities," Inte.J.Elec.Power Eng, vol.3, 2009, pp.112-118.

[12] K Jagatheesan, B Anand, "Dynamic Performance of Multi-Area Hydro Thermal Power Systems with Integral Controller considering various performance Indices methods," Proceedings of the IEEE International conference of Emerging trends in Science, Engineering and Technology (INCOSET), 2012, pp.474-478 
[13] I.J. Nagrath, D.P. Kothari, "Power system engineering", Tata Mc-Graw Hill Publishing Company limited, 1994, New Delhi, India.pp.320-344

[14] P.Kundur, "Power system stability and control", Tata Mc-Graw Hill Publishing company limited, 1994, New Delhi, India.pp.581-626

[15] O.I.Elgerd, "Electric Energy System Theory: An Introduction", Tata Mc-Graw Hill Publishing company limited,, New York,1970. Pp.315-389. 